\title{
Pharmacist Clinical Process Improvement: Applying Lean Principles in a Tertiary Care Setting
}

\author{
Jennifer Shiu and Tania Mysak
}

\section{INTRODUCTION}

$\mathrm{P}$ roviding quality health care efficiently is challenging. One quality improvement approach, which originated in the manufacturing sector, is Lean. Lean is a set of principles and tools used to create a culture of improvement. Essential principles of Lean management include continuous improvement, creating value by eliminating waste, finding purpose, front-line innovation, using visual standards, and implementing standard work or standardized process steps. ${ }^{1,2}$ Although these principles are readily applicable to manufacturing processes, they need to be adapted for use in health care. The focus of Lean in health care has been to define value, map value streams, and reduce or eliminate non-value-added activities or wastes. ${ }^{3}$ Workflow improvements result from identifying and reducing wastes, where major waste categories include defects, motion, transportation, overprocessing, overproduction, inventory, unused talent, and waiting. ${ }^{2,4}$ Using Lean methodology in health care to look for (and then eliminate) wastes is not new.

Lean principles have been applied to numerous health care settings, where they have resulted in positive outcomes. Planning and implementing improvements related to coordinating discharge activities, increasing communication, and improving workflow (e.g., daily pick-up of referrals) have resulted in decreased readmission rates, improved patient satisfaction, decreased time to see referred patients, and decreased length of stay. ${ }^{5-7}$ Previous work applying Lean principles within pharmacy has related mainly to distribution processes. Using techniques to reduce waste and improve workflow has resulted in fewer missing doses, cost savings, and decreases in medication errors, patient-specific waste, medication turnaround times, pharmacist verification time, product verification time, and medication delivery time. ${ }^{8-13}$ As one example, process improvement work in the sterile products and inventory area of a university hospital decreased missing doses by 30\%, errors by $50 \%$, and patient-specific waste by $30 \% .^{9}$ At a US Department of Veterans Affairs hospital that implemented A3 thinking (a structured problem-solving approach), the average time from entry of a stat order to medication administration declined by $21 \%$, and the total time from medication delivery to administration was reduced by $26 \% .{ }^{10}$ Workspace and process redesign and development of standard operating procedures at the Weinberg Pharmacy in the Sidney Kimmel Cancer Center, Baltimore, Maryland, resulted in a decrease in medication errors (from $50 \%$ to $41 \%$ ). ${ }^{11}$ A community hospital in Ontario improved medication administration safety and implemented actions such as synchronizing fax machine clocks, standardizing pharmacy order entry, taking medication administration records to the bedside, and using a chart-flagging system, which decreased the rate of serious medication events from 1.3 to 0.007 events per 10000 orders. ${ }^{12}$ Another quality improvement project, conducted at the Smilow Cancer Hospital in New Haven, Connecticut, used strategies such as failure mode and effects analysis, workflow mapping, and impact analysis to identify opportunities to decrease waste. ${ }^{13}$ These efforts decreased time required for pharmacist verification by $33 \%$, time required for product verification by $52 \%$, and average time for medication delivery by $47 \% .{ }^{13}$ It is clear that there are many benefits to applying Lean principles to pharmacy distribution processes. However, few projects have addressed clinical processes.

Lean methodology states that waste or non-value-added activities can be identified in any process, including clinical processes. In a Lean "waste walk" study, in which 20 clinical pharmacists were observed and their activities categorized as waste or non-waste, $23.8 \%$ of observations were categorized as waste. ${ }^{4}$ Although the study identified potential wastes, it did not implement any steps to improve efficiency. Other projects 
investigating the potential impact of Lean on clinical pharmacists have shown that benefits in the dispensary process will free up time for clinical work, but the authors have not discussed how to improve efficiency. At the Royal Bolton Hospital NHS Foundation Trust, use of the Lean approach identified numerous benefits, including a $25 \%$ reduction in dispensary rework, which the authors indicated would allow for more time in clinical areas. ${ }^{14}$ However, this project did not elaborate on clinical processes. At the Royal Jubilee Hospital in Victoria, British Columbia, a Lean project to streamline drug distribution processes allowed for integration of a clinical pharmacist and pharmacy assistant into a renal ward. ${ }^{15}$ Although it supported clinical work, this project was not designed to evaluate the efficiency of pharmacists' clinical processes.

The current study was undertaken to identify potential wastes in clinical pharmacist processes in a tertiary care setting and to reduce or eliminate them, where possible, to improve efficiency.

\section{DESCRIPTION OF PRACTICE OR PROGRAM}

The University of Alberta Hospital in Edmonton, Alberta, has 4 interdisciplinary General Internal Medicine (GIM) teams. Discussion with clinical pharmacists identified variability in workload management, with some activities being thought of as non-value-added. In addition, the GIM pharmacists reported not being able to complete their daily workload within a standard clinical shift, which resulted in decreased team engagement (evidenced by decreased communication between pharmacists and site leaders and decreased participation in site initiatives) and potentially increased injuries, sick time, and mistakes. The amount of workload not completed within each clinical shift varied among pharmacists, but included medication histories, initial and follow-up patient assessments, and chart documentation. From February to November 2014, a process improvement project was conducted using Lean methodology to evaluate the efficiency of clinical pharmacist practice and to implement solutions to improve clinical workflow and consistency.

During this period, 5 clinical pharmacists rotated through 4 standard 7.25-h clinical shifts distributed among the 4 teams. All pharmacists included in this study voluntarily agreed to participate and to share information about their clinical activities. Each pharmacist attended an introductory session outlining the basic Lean principles, and each was asked to collect data on daily activities using a standard tool (Appendix 1, available at www.cjhp-online.ca/index.php/cjhp/issue/view/ 120/showToc) for 3 days. The standard tool collected information about activity type, such as seamless care and documentation, time spent on each activity, and the location where each activity was performed. Through discussion and review of the data collected, the GIM pharmacists and authors created a current- state value stream map. The GIM pharmacists then brainstormed potential solutions to address activities or process steps identified as non-value-added and to maximize value-added activities that were within the control of the pharmacy department. The pharmacists also discussed the ideal future state and identified opportunities for improvement. A previous project entitled the GIM Care Transformation Initiative ${ }^{16}$ included consultants interviewing and surveying patients and interdisciplinary team members about pharmacist activities perceived as value-added, and this information was also taken into consideration. Potential solutions were prioritized and action plans were created, with responsibilities assigned to stakeholders and timelines set to ensure that work was completed within 4 months. Action plans were prioritized according to those solutions that were "quick wins", to build team confidence. Only those activities within the scope of the pharmacy department were selected.

A planned follow-up meeting took place 4 months after the current-state value stream mapping session, to discuss qualitative improvements and postimplementation data. Before this meeting, each pharmacist was asked to again collect data on daily activities for 3 days, to create a postimplementation value stream map. Progress on action plans and on sustaining results through creation of standard work documents was discussed.

\section{EVALUATION OF THE PROGRAM}

Using the baseline data collected by the GIM pharmacists and discussed by the project team, a current-state value stream map was created (Figure 1). This process showed that within a pharmacist's shift, excluding breaks, a total of 435 min was available to complete activities. Value-added activities were those activities that directly contributed to patient care, such as patient rounds, patient work-up, and team follow-up. Nonvalue-added activities were those activities that were considered duplication of work or not directly contributing to patient care. Other terms used in creating these maps are available in the glossary (Box 1). The definitions of value-added and nonvalue-added activities were based on Lean principles, whereby assigning value to process steps is directly related to the benefit to the customer (i.e., patient). Pharmacists' daily activities were reviewed and assigned to each category on the basis of discussion with the pharmacists and benefit to patient care. It was determined that $39 \%$ of activities in the process were non-value-added, with 4 main causes. First, the Best Possible Medication History (BPMH) was being redone by the pharmacists daily because histories taken by medical students or residents were often incomplete or inaccurate. Second, pharmacists were reviewing the same information in multiple sources (e.g., Netcare [Alberta's provincial electronic health care record]) and were also reviewing information for which other 
A
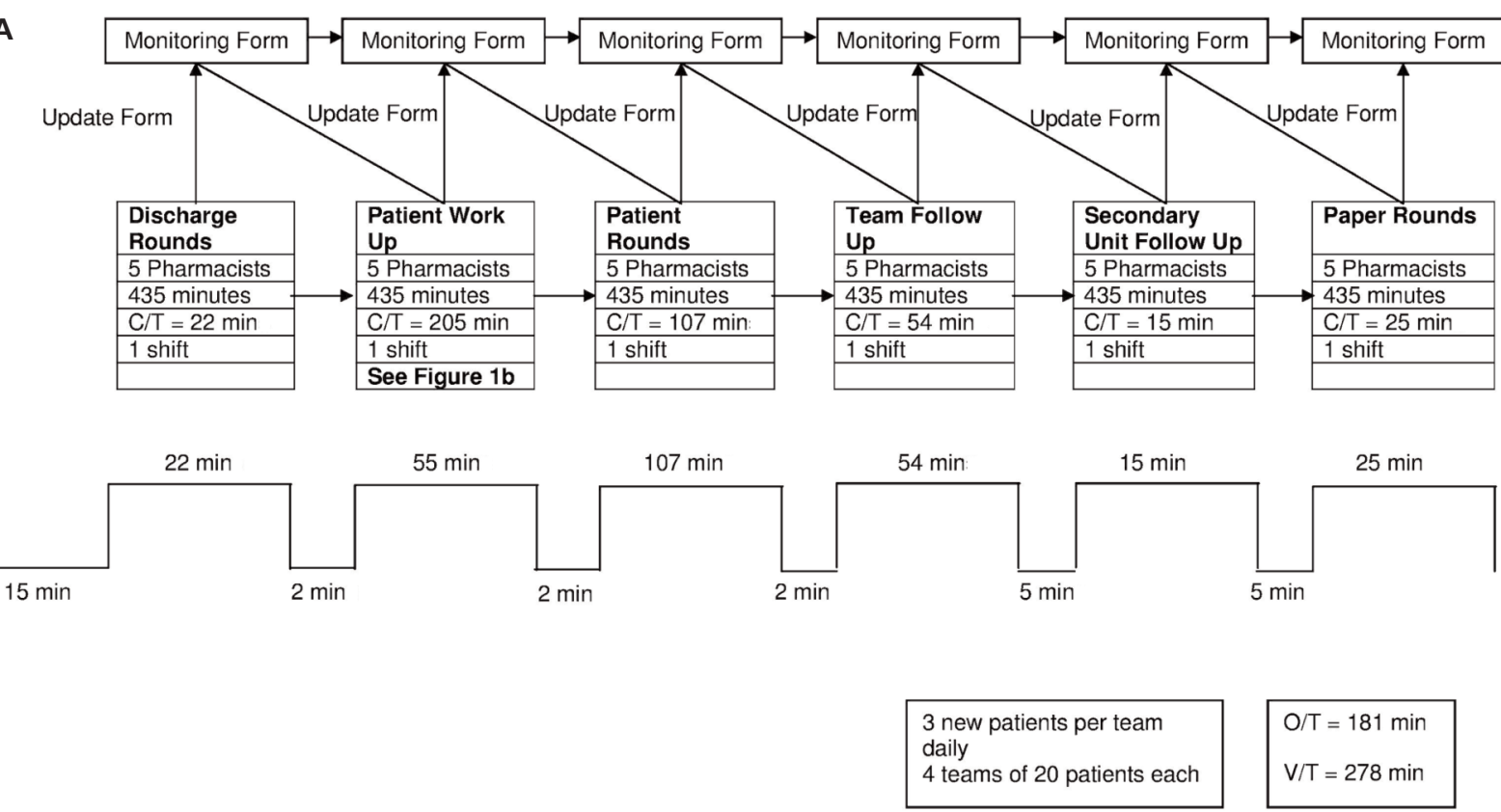

$\mathrm{O} / \mathrm{T}=181 \mathrm{~min}$

$\mathrm{V} / \mathrm{T}=278 \mathrm{~min}$
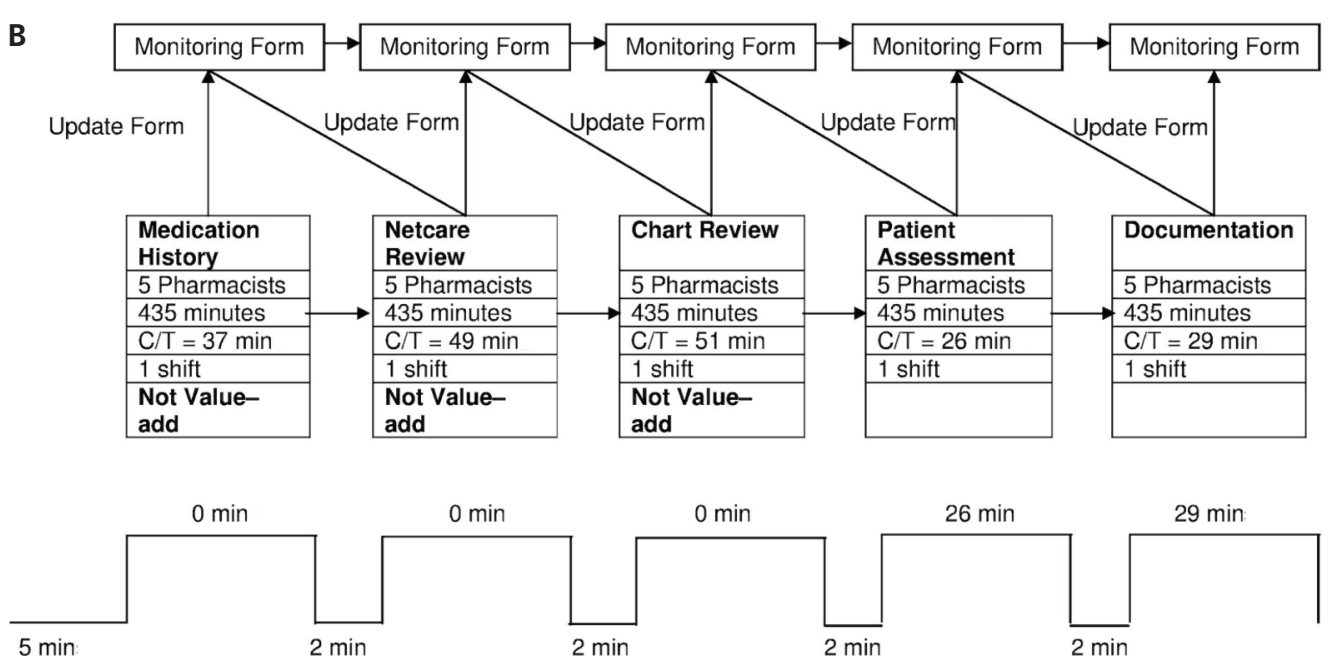

$5 \min$

$2 \min$

$2 \min$
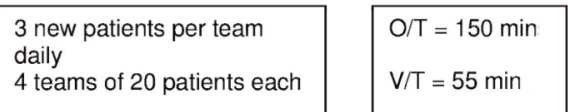

Figure 1. (A) Current-state value stream map at baseline. (B) Current-state patient work-up at baseline. $C / T=c y c l e ~ t i m e$, $\mathrm{O} / \mathrm{T}=$ opportunity time, $\mathrm{V} / \mathrm{T}=$ value-added time.

team members were responsible or that was available on patient rounds. Third, there was duplicate documentation of information already charted by other team members. Fourth, pharmacists were completing patient monitoring forms that were not retained as part of the patient record. These forms were intended to help with patient assessment, but completing them often resulted in either omission of the information from documentation in the patient chart (even when it was required) or duplication of work (when the information was recorded on both the monitoring form and in the patient record).

After the main causes of non-value -added activities were identified, the GIM pharmacists discussed potential opportunities for improvement, taking into consideration the ideal future state. For example, it was felt that there was opportunity to 


\section{Box 1. Glossary of Lean terminology}

Cycle time (C/T): Time for each process step to be completed; for example, time taken to complete a medication history.

Lead time: Sum of value-added time plus opportunity time; for example, the total time spent working during a clinical shift.

Opportunity time (O/T): Non-value-added time that cannot be removed from the process; for example, the time taken to perform activities not directly contributing to patient care, such as travel time between units.

Value-added time (VIT): Time spent on activities that directly contribute to patient care; for example, time spent on patient assessment.

cross-train and re-educate interdisciplinary team members about the BPMH and admission medication reconciliation process. The pharmacists identified parts of the patient review process involving duplication of work that could be reduced or eliminated. There was also an opportunity to standardize work (to streamline documentation or internal pharmacist-topharmacist patient handover) and to eliminate or reduce the use of monitoring sheets. The GIM pharmacists agreed upon the action plans created for each potential solution identified.

Follow-up data collected by the GIM pharmacists 4 months after implementation of the action plans were used to create a follow-up value stream map (Figure 2). It was found that the lead time (value-added time plus opportunity time) decreased from 459 to $428 \mathrm{~min}$. In other words, before the Lean project, it took each pharmacist about 459 min or $7.65 \mathrm{~h}$ to complete their work each day, excluding breaks, but after the Lean project, less time was required. The decrease in lead time was primarily due to the decrease in opportunity time (nonvalue-added time that could not be removed from the process, such as travel time or chart review), from 181 to $146 \mathrm{~min}$. Efficiencies in the patient work-up and patient rounds steps accounted for the majority of the decrease. The remaining 146 min of opportunity time was due to factors not within the control of the GIM pharmacists, such as walking to different wards for patient assessment and incomplete documentation by the multidisciplinary team, which required the pharmacist to find patient information in the chart or laboratory results system. The value-added time increased from 278 to $282 \mathrm{~min}$, which was expected because of improved efficiencies introduced into the system. Of note, time spent on re-doing BPMHs decreased from 37 to $15 \mathrm{~min}$ through cross-training of other staff, which increased time available for patient assessment from 26 to $41 \mathrm{~min}$. Therefore, within 4 months of applying Lean methodology, improvements were made that allowed for a decrease of $31 \mathrm{~min} /$ day for each pharmacist, while increasing time for patient assessment. The time saved also allowed the pharmacists to take their allotted breaks and perform all of their tasks within a standard shift.

\section{IMPLICATIONS AND SIGNIFICANCE FOR PRACTICE}

This was one of the first projects within the hospital setting in Alberta to apply Lean principles to the workflow processes of clinical pharmacists. In this study, a reduction of $31 \mathrm{~min} /$ day for each pharmacist was achieved by eliminating or decreasing non-value-added activities. Clinical efficiency was improved over a 4-month period, while more time was provided for patient assessment.

Although this study showed positive results, there are still uncertainties about the benefit of Lean methodology in health care. A systematic review of 22 studies using Lean processes, with quantitative data for health outcomes, process outcomes, or both health and process outcomes, did not show statistically significant results, although the data were too diverse for a meta-analysis. ${ }^{17}$ Nonetheless, the authors found that there was no association between Lean methods and patient satisfaction or health outcomes. ${ }^{17}$ Also, there might have been a negative association with costs and employee satisfaction. ${ }^{17}$ Finally, the review showed inconsistent benefits in terms of patient flow and safety. ${ }^{17}$ Another systematic review of 7 literature reviews summarized the implementation of Lean methods in acute care and their impact, ${ }^{18}$ suggesting that Lean principles are better suited to linear processes. Of note, the quality of the evidence included was rated as poor to fair, which is a common limitation in studying the impact of Lean projects. The main limitations included a lack of controlled study designs, a lack of statistical analyses, and a lack of longitudinal studies. ${ }^{18}$

The limitations of the current study are similar to those previously identified. There was no control group, and no statistical analyses were conducted. Although gains were achieved through this project, such as implementation of standard work, which improved consistency, these benefits are not easily quantified. As well, the follow-up period was short, which did not allow for assessment of the sustainability of results. Also, because data collection was self-reported by each pharmacist, reporting bias may have affected the outcomes studied. However, it was noted through discussion that variability in practice from one pharmacist to another was minimal. One of the biggest challenges encountered during this project was identifying outcomes that could be measured accurately and that would be meaningful to clinical practice. As well, clinical outcomes are difficult to study without adjusting for other organizational changes that may be occurring at the same time. One possible method to identify value-added practices in specific patient populations is a concept called "quality actions". ${ }^{19}$ The criteria suggested for selecting quality actions include evidence strength, effectiveness, safety, and efficiency. ${ }^{19}$ As well, pharmacist activities could be prioritized on the basis of a conceptual value index that considers the prevalence of a problem in a patient population, quality 
A
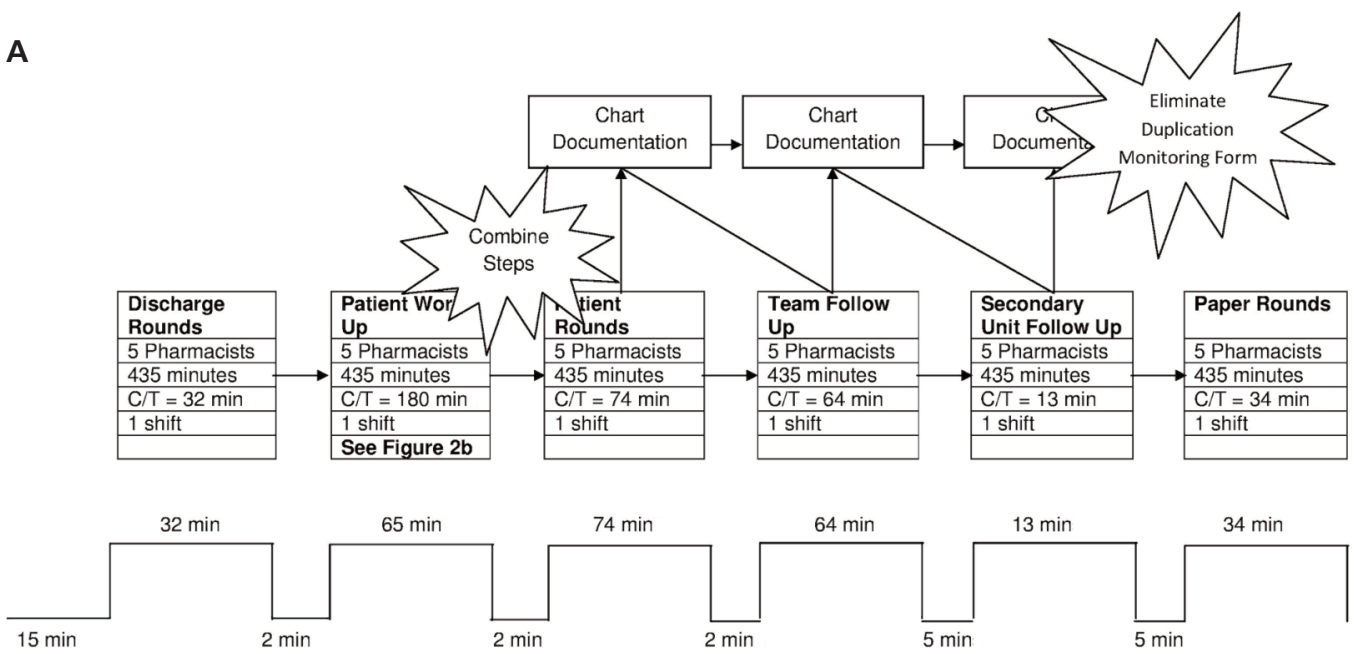

4 teams of 20 patients each

B
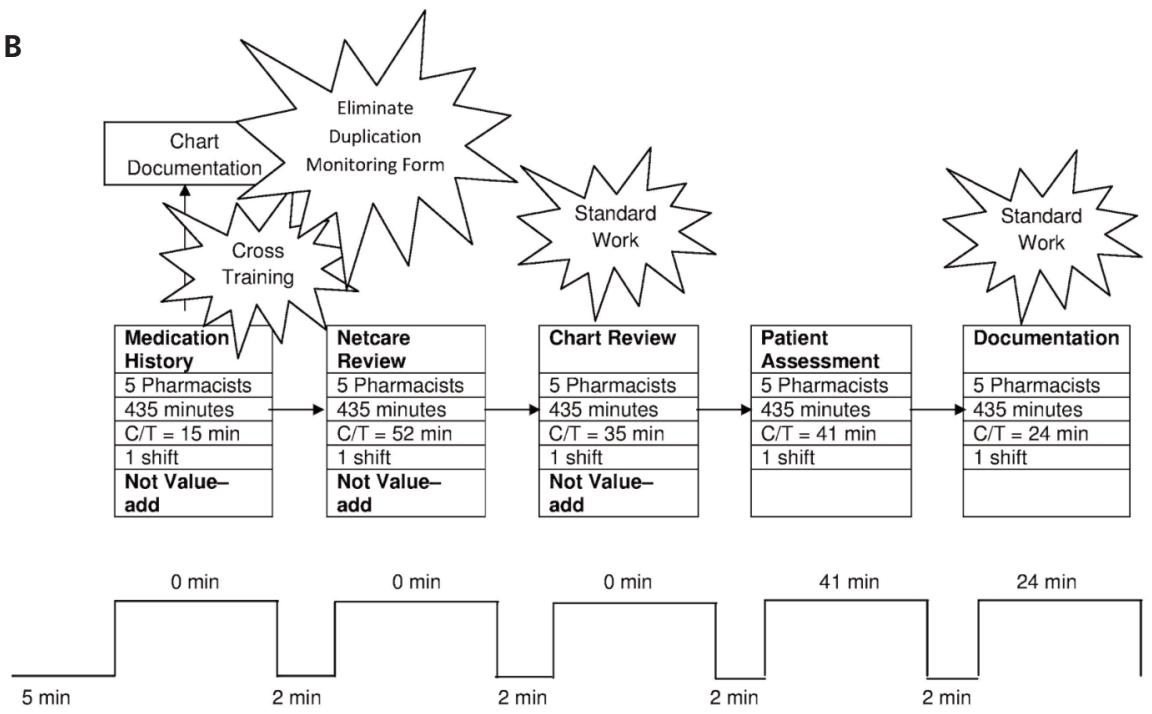

$5 \mathrm{~min}$
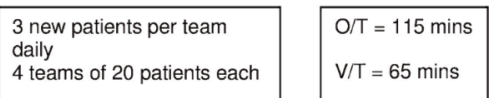

Figure 2. (A) Follow-up value stream map at 4 months. (B) Follow-up patient work-up at 4 months. $\mathrm{C} / \mathrm{T}=$ cycle time, $\mathrm{O} / \mathrm{T}=$ opportunity time, $\mathrm{V} / \mathrm{T}=$ value-added time .

indicators, and the effort needed to manage the problem. ${ }^{19}$ While important, creating such a conceptual value index would be difficult to do in practice.

Despite these limitations, clinical process improvement projects are important because they support pharmacists in achieving an efficient, full scope of practice without compromising patient care. Such projects also support the principles of reducing time spent on duplicate activities and promoting time spent in front of patients. Lean methodology also helps to establish clear, consistent processes that facilitate training of new staff and cross-coverage of clinical teams. Future quality improvement projects looking at pharmacists' clinical practice should define more rigorous study methods, including a method to measure the impact of proposed changes. Identification and analysis of practice-related outcomes is needed to better measure the success of Lean interventions. In addition, 
there is opportunity to explore issues related to the sustainability of these projects, as this type of information is poorly described in the existing literature. As clinical pharmacist practice continues to evolve, there will be a growing need to re-evaluate current processes and find efficiencies.

\section{References}

1. Toussaint JS, Berry LL. The promise of Lean in health care. Mayo Clin Proc. 2013;88(1):74-82

2. Teich ST, Faddoul FF. Lean management-the journey from Toyota to healthcare. Rambam Maimonides Med J. 2013;4(2):e0007.

3. Poksinska B. The current state of Lean implementation in health care: literature review. Qual Manag Health Care. 2010;19(4):319-29.

4. Green CF, Crawford V, Bresnen G, Rowe PH. A waste walk through clinical pharmacy: how do the 'seven wastes' of Lean techniques apply to the practice of clinical pharmacists. Int J Pharm Pract. 2015;23(1):21-6.

5. Breslin SE, Hamilton KM, Paynter J. Deployment of Lean Six Sigma in care coordination: an improved discharge process. Prof Case Mang. 2014;19(2): 77-83.

6. Wackerbarth SB, Strawser-Srinath JR, Conigliaro JC. The human side of lean teams. Am J Med Qual. 2015;30(3):248-54.

7. Atkinson P, Mukaetova-Ladinska EB. Nurse-led liaison mental health service for older adults: service development using lean thinking methodology. J Psychosom Res. 2012;72(4):328-31.

8. Lingaratnam S, Murray D, Carle A, Kirsa SW, Paterson R, Rischin D. Developing a performance data suite to facilitate lean improvement in a chemotherapy day unit. J Oncol Pract. 2013;9(4):e115-21.

9. Hintzen BL, Knoer SJ, Van Dyke CJ, Milavitz BS. Effect of lean process improvement techniques on a university hospital inpatient pharmacy. Am J Health Syst Pharm. 2009;66(22):2042-7.

10. Manojlovich M, Chase VJ, Mack M, Conroy MK, Belanger K, Zawol D, et al. Using A3 thinking to improve the STAT medication process.J Hosp Med. 2014;9(8):540-4.

11. Aboumatar HJ, Winner L, Davis R, Peterson A, Hill R, Frank S, et al. Applying Lean Sigma solutions to mistake-proof the chemotherapy preparation process. Jt Comm J Qual Patient Saf. 2010;36(2):79-86.

12. Critchley S. Improving medication administration safety in a community hospital setting using Lean methodology. J Nurs Care Qual. 2015;30(4): $345-51$.
13. Sullivan P, Soefje S, Reinhart D, McGeary C, Cabie ED. Using lean methodology to improve productivity in a hospital oncology pharmacy. Am J Health Syst Pharm. 2014;71(17):1491-8.

14. Smith B. Using the Lean approach to transform pharmacy services in an acute trust. Pharm J. 2009;282:457.

15. Lorimer HJ, Lalli SL, Spina SP. Redesign of the pharmacy practice model at a tertiary care teaching hospital. Can J Hosp Pharm. 2013;66(1):28-34.

16. McAlister FA, Bakal JA, Majumdar SR, Dean S, Padwal RS, Kassam N, et al. Safely and effectively reducing inpatient length of stay: a controlled study of the General Internal Medicine Care Transformation Initiative. BMJ Qual Saf. 2014;23(6):446-56

17. Moraros J, Lemstra M, Nwankwo C. Lean interventions in healthcare: do they actually work? A systematic literature review. Int $J$ Qual Health Care. 2016;28(2):150-65.

18. Deblois S, Lepanto L. Lean and Six Sigma in acute care: a systematic review of reviews. Int J Health Care Qual Assur. 2016;29(2):192-208.

19. Bruchet N, Loewen P, de Lemos J. Improving the quality of clinical pharmacy services: a process to identify and capture high-value "quality actions". Can J Hosp Pharm. 2011;64(1):42-7.

Jennifer Shiu, BSCPharm, PharmD, ACPR, is Clinical Practice Leader, Alberta Health Services, Edmonton, Alberta.

Tania Mysak, BSP, PharmD, is Director, Practice, Pharmacy, Alberta Health Services, Edmonton, Alberta.

Competing interests: None declared.

\section{Address correspondence to:}

Dr Jennifer Shiu

Pharmacy Services

University of Alberta Hospital

5F1.23 Walter C Mackenzie Centre

8440 - 112 Street

Edmonton $A B$ T6G $2 B 7$

e-mail: jennifer.shiu@ahs.ca

Funding: None received.

Acknowledgements: The authors would like to thank Gordon Bell, Wilson Cheng, Mui Yin Lee, Jany Lou, Mandeep Plaha, Cindy Polivchuk, and Jane Xu for their participation and support. 